anales de psicología, 2018, vol. 34, $\mathrm{n}^{\circ} 2$ (mav), 224-232 http://dx.doi.org/10.6018/analesps.34.2.289741
(C) Copyright 2018: Editum. Servicio de Publicaciones de la Universidad de Murcia. Murcia (Spain) ISSN print edition: 0212-9728. ISSN web edition (http://revistas.um.es/analesps): 1695-2294

\title{
Low levels of morning salivary $\alpha$-amylase activity predict higher number of depressive symptoms in a community sample of children
} \author{
Carmen Ortíz ${ }^{2}$, Alfredo Enguix ${ }^{2}$, and Mari Nislin ${ }^{3}$ \\ 1 University of Malaga (Spain) \\ 2 Virgen de la Victoria Hospital, Malaga (Spain). \\ 3 The Education University of Hong Kong (Hong Kong).
}

Enrique Francisco Maldonado ${ }^{1 *}$, Eugenia Fernández ${ }^{1}$, María Victoria Trianes ${ }^{1}$,

\begin{abstract}
Título: Bajos niveles de actividad alfa-amilasa salivar predicen un número más elevado de síntomas depresivos en una muestra infantil comunitaria. Resumen: Los modelos sobre la etiología de los trastornos depresivos sugieren que el inicio de un episodio depresivo es el resultado de un complejo fenómeno que se basa en la interacción entre la carga genética, factores ambientales críticos tales como eventos vitales estresantes y traumáticos, y el efecto de los cambios neuroendocrinos asociados con la respuesta de estrés. Numerosos estudios han resaltado la utilidad de los niveles matutinos de cortisol (C) como un potencial predictor de episodios depresivos. El objetivo del estudio fue comparar la efectividad del C, de la actividad/secreción de la alfa-amilasa salivar (AAs) y de su ratio para predecir la sintomatología depresiva en una muestra comunitaria de 99 niños con edades entre los 8-11 años. Dos muestras de saliva fueron obtenidas en la mañana en dos días escolares. Los profesores describieron el comportamiento de sus estudiantes usando la escala Teacher's Report Form (TRF). Nuestros resultados indican que, con independencia del género, el mejor predictor de las puntuaciones de depresión/aislamiento y del total de alteraciones internalizadas del TRF fue mostrar bajos niveles de actividad de AAs en la mañana. Por lo tanto, esta medida salivar podría ser usada como un marcador biológico del riesgo para el desarrollo de un primer episodio de depresivo infantil.
\end{abstract}

Palabras clave: Alfa-amilasa; Cortisol; Síntomas Depresivos; Estudio Observacional Descriptivo.

\section{Introduction}

The stress system in humans is responsible for a double response - hormonal and neural - that, under the perception of a certain stimulus or situation as stressful, involves the activation of the sympathetic adrenomedullar system (SAM) and of the hypothalamus-pituitary-adrenal (HPA) axis (Sapolsky, 2000). The SAM system produces changes in the Autonomous Nervous System (ANS) and an elevation of peripheral adrenaline and noradrenaline levels (Chrousos, 2009). As a final output, the HPA axis causes an elevation in cortisol levels (C; Chousos, 2009; Sapolsky, 2000). Free C measurement in saliva was introduced in psychosomatic research in the 1980's as an easy and ecologically valid way of obtaining an objective measurement of HPA axis activity (Kirschbaum \& Hellhammer, 1989). More recently, measurement of the activity and/or output of the salivary enzyme alpha-amylase (sAA) has been proposed as a new, indirect marker for ANS activation and peripheral noradrenaline produced by stressful situations (Ditzen, Ehlert, \& Nater, 2014; Nater \& Rohleder, 2009; Rohleder \& Nater, 2009).

* Correspondence address [Dirección para correspondencia]:

Enrique Francisco Maldonado. University of Malaga, Andalucia Tech, School of Psychology, Deparment of Psychobiology and Methodology of the Behavioral Sciences, Campus de Teatinos, 29071, Malaga (Spain). E-mail: fcomm@uma.es
Abstract: Models of the etiology of depressive disorders suggest that the onset of a depressive episode is the result of a complex phenomenon based on the interaction between genetic background, critical environmental factors such as life stressors and traumatic events, and the effects of neuroendocrine changes associated with the stress response. Numerous studies have highlighted the usefulness of morning cortisol (C) as a potential predictor of depressive episodes. The aim of this study was to compare the effectiveness of $\mathrm{C}$, salivary alpha-amylase (sAA) activity/output, and the $\mathrm{sAA} / \mathrm{C}$ ratio in predicting depressive symptoms in a community sample of 99 children aged 8-11 years old. Two saliva samples were obtained in the morning on two different school days. Teachers described their pupils' behavior by using the internalizing problems scales of the Teacher's Report Form (TRF) questionnaire. Our results indicate that, regardless of gender, the best predictor of depressive/withdrawal scores and overall internalizing scores on the TRF was lower mean morning levels of sAA activity. Hence, sAA could be proposed as a biological marker for the risk of developing a first episode of depressive illness in child samples.

Keywords: Alpha-Amylase; Cortisol; Depressive Symptoms; Children; Observational Descriptive Study.

sAA is usually measured through its enzymatic activity on a substrate or by its production and secretion in saliva over a defined period of time (Rohlerder \& Nater, 2009). As in the case of $\mathrm{C}$, sAA can be measured in the morning or as a circadian profile over the course of the day (Nater \& Rohleder, 2009). The salivary alpha-amylase awakening response (sAAAR), a morning measurement of sAA, comprises two distinct phases. First, a decrease in levels of sAA activity/output from awakening time to the $+30 \mathrm{~min}$ measurement is observed. There is then a sharp increase in sAAAR from the $+30 \mathrm{~min}$ measurement to the +60 min measurement. This is then followed by a progressive, intense increase in levels of sAA enzymatic activity through midday or the afternoon hours what ultimately decrease in the final hours of the day to their lowest levels (see Nater \& Rohleder, 2009 and Rohleder \& Nater, 2009 for more details).

Over the past 20 years, in this field of scientific work (i.e. the study of the human stress system response and its shortand long-term psychological effects), different research groups have created predictive models for identifying risk factors for child and adolescent depression. Some of this research has specifically combined the theoretical framework of the diathesis-stress model and the study of interaction among gender, genetic background and the impact of day-today and life stressors with neuroendocrine changes to explain and predict triggering of the first major depressive episode 
(MDE) (Kendler \& Gardner, 2014; Kuhlman, Olson, \& Lopez-Duran, 2014; O’Donnell et al., 2013).

\section{Review of studies aimed at such objectives using sAA and C}

Based on this theoretical framework, a number of relevant studies have focused on the specific interaction between day-to-day and life stressors and the HPA axis stress responses they elicited to predict the development of the first MDE. In 1996, Goodyer and colleagues showed that high levels of evening cortisol (at 20:00), low levels of salivary dehydroepiandrosterone (DHEA) in the morning (at 8:00), or a high cortisol/DHEA ratio in the evening or at midnight (at $20: 00$ or at $24: 00$ ) were present in $50 \%$ of children or adolescents diagnosed with a first MDE. These associations were not affected by age or gender differences in this cohort of 147 participants. Moreover, about $50 \%$ of these children and adolescents remained depressed at follow-up, 36 and 52 weeks later (Goodyer et al., 1996; Herbert et al., 1996) and, in a smaller selection of this cohort, an association between evening cortisol and co-morbid dysthymia emerged (Goodyer, Herbert, \& Altham, 1998). In line with these seminal works, a delayed recovery (flat diurnal rhythm of cortisol) and possibly a reduced cortisol awakening response (CAR) (multiple measurements of morning cortisol levels with strict respect to waking time; see Nater \& Rohleder, 2009 for a review) could be considered as reliable indicators of a more general risk status and may be part of a commonly-used method for determining psychopathology that is also used by other research groups (Merwin, Smith, Kushner, Lemay \& Dougherty, 2017; Nederhof et al., 2015; Van den Bergh \& Van Calster, 2009).

In contrast with these results, another body of evidence that is currently emerging has pointed out that high morning levels of cortisol could be considered a risk factor for a MDE. For example, in one of these studies, Halligan, Herbert, Goodyer, \& Murray (2004) reported that adolescents (13 year-olds; $n=87$ ) whose mothers were diagnosed with postpartum depression exhibited a greater number and/or more severe levels of depressive symptoms and an elevated CAR, but not elevated evening levels of cortisol. These differences were accompanied by more variability in cortisol levels relative to controls during the observation period. In a later phase of the same study, these authors reported that children of mothers diagnosed with postpartum depression exhibited higher levels of morning cortisol at 13 years of age, which was the factor that best predicted the level of depressive symptomology at the age of 16 . These associations were independent of confounders such as gender, BMI, and Tanner Stages (Halligan, Herbert, Goodyer, \& Murray, 2007). Thus, depressive symptoms observed during adolescence were statistically mediated by morning cortisol levels at the age of 13. A closely-related finding in female participants was recently reported by Adam et al. in 2010. Dietrich et al. (2013) confirmed this same association between morning cortisol levels and CAR with depressive problems in a cohort of 1604 adolescents. Nevertheless, the relationship was weaker than previously assumed and, in analyses of the clinical subsample, the association was found to be stronger among male participants. A similar conclusion was reached by Vrshek-Schallhorn et al. (2013) and Nelemans et al. (2014). Finally, Keenan et al. (2013) studied the specific association between the cortisol response to a laboratory stressor and depressive symptomatology in a cohort of 232 girls at 10 years and 12 years of age and their mothers. They reported that associations between HPA axis functioning and depression emerged around age 12.

Recent findings in this particular field of research have demonstrated that higher morning cortisol levels could also be associated with a greater risk of depression even in much younger children. For example, Dougherty, Klein, Olino, Dyson, \& Rose (2009) reported that postpartum depression in mothers was associated with a higher level of cortisol and lower positive emotional temperament in 94 healthy boys and girls (aged 3-4 years). This result was independent of confounders such as age or gender. In a subsequent study, Dougherty et al. (2013) reported that higher negative emotional temperament at age three predicted high morning cortisol levels three years later. Interestingly, these authors proposed that these psychobiosocial characteristics could, as a whole, increase the risk of triggering a future MDE.

Although the studies reviewed in the previous paragraphs highlight the usefulness of cortisol in particular (especially when it is measured in form of the CAR) as an early predictor of a future triggering of a first MDE in adolescents (without gender differences in the majority of the reviewed studies), a recent and robust epidemiological study that examined a wide cohort showed that the predictive capacity of morning cortisol levels could be influenced by gender, thereby increasing misunderstanding of these initial results $(\mathrm{Ow}-$ ens et al., 2014). Specifically, these researchers observed that in the total sample of 1858 participants, morning cortisol was associated with a high risk of depression exclusively in male participants. Given the higher prevalence of depression in adolescent girls (Domench-Llaberia et al., 2009; FonsecaPedrero, Paino, Lemos-Giráldez, \& Muñiz, 2011; Mendes et al., 2012; Weissman et al., 2006), these groups of results (Lewis, Jones, \& Goodyer, 2016; Nelemans et al., 2014; Owens et al., 2014) should alert us of the need to shift the focus of our attention towards the search for further sensitive biomarkers of early depression risk in girls. In line with this search for new, more precise biological markers of depression, the usefulness of sAA as a low-cost, biological marker of psychopathology has become a relevant new line of research, especially over the two last decades. Unfortunately, the results published on the utility of the association of $\mathrm{sAA}$ activity/output with depressive symptoms and/or symptoms of anxiety specifically are still scarce and inconclusive in adult and child populations (Bagley, Weaver, \& Buchanan, 2011; Braithwaite, Ramchamandani, Lane, \& Murphy, 2015; Ishitobi et al., 2010; Tanaka et al., 2012; Veen et al., 2013). 
Interestingly, the only study on this issue to focus on a child and adolescent population showed an inverse relationship between baseline sAA activity and depressive symptoms in male adolescent survivors of Hurricane Katrina (Vigil, Geary, Granger, \& Flinn, 2010). As in the previouslyreviewed studies that use C, the full meaning of Vigil et al.'s results will be made clear only by understanding the multiple interactions among genetic background, life stressors, and gender. Likewise, in line with the search for more sensitive biomarkers of depression risk, and according to principles of the interactive model of the function of the stress system, Bauer, Quas, \& Boyce (2002) have suggested that the use of $\mathrm{sAA} /$ cortisol and/or cortisol/sAA ratios could be more sensitive biological measurements of anxious and depressive feelings associated with these internalizing disorders in comparison with a single measurement of any or both aspects of this biological response. (Ali \& Pruessner, 2012; Bauer et al., 2002; Blair, Granger, \& Razza, 2005; Vigil et al., 2010).

Based on all the aforementioned results, the main aim for our study was to estimate the potential relative usefulness of morning cortisol, sAA activity, sAA output, and the ratios of sAA activity-output/cortisol in predicting levels of depressive symptoms in a community sample composed of 54 girls and 45 boys aged $8-11$ years.

\section{Material and Methods}

\section{Participants}

Participants in our cross-sectional study $(n=99)$ were selected from an initial pool of 116 children attending a public school in the metropolitan area of Malaga (Spain). According to parental reports, all of the children were in good general health with the exception of 17 , who were excluded from this study because they were taking prescription medication with endocrine, immunological, or neurological effects or had a major illness. Thus, the final sample comprised 45 boys and 54 girls. The study was conducted according to the principles set forth in the Declaration of Helsinki. Informed consent was obtained in writing from the parents (fathers and/or mothers) of each participant in our study.

\section{Procedure}

Before data collection, we organized a briefing for the children's parents and provided them all the necessary information about the aims of this research. Special attention was paid to the following four points: (a) instruction of parents and children on the correct timing of saliva sampling on awakening and +30 min later; (b) avoidance of food or liquids (except water) and refraining from brushing teeth during the time of saliva sampling; (c) appropriate conservation of saliva samples in the home freezer; and (d) a record sheet kept by the parents to note any violations of this protocol. Parents filled out a questionnaire which provided anthropometric and socio-demographic data on their child. Home sa- liva samples were collected over two typical school days (freely chosen by the parents, but always in the same week before psychological assessment) along with information about the sleeping habits of the participant.

\section{Psychological measures}

We employed the Achenbach System of Empirically Based Assessment (ASEBA) for school-age children and adolescents to assess the children's emotional and/or behavioral problems and social competencies. In this study, only the results from the internalizing scales of the Teacher's Report Form (TRF) were used. Only those teachers who had a minimum of one academic year of experience with the student provided information on the behavior of each participant. The name and composition of the three internalizing subscales of TRF are: anxious/depressed (Cronbach's $\alpha=0.97$; indicated as $\mathrm{TRF}_{\text {anxiety }}$ in Tables 1, 2, and 3) with 8 items; withdrawn/depressed (Cronbach's $\alpha=0.79$; shown as TRF depression. $_{\text {- }}$ withdrawal in Tables 1, 2, and 3) with 8 items, and somatic complaints (Cronbach's $\alpha=0.97$; indicated as TRF psychosomatic in Tables 1, 2, and 3) with 9 items. These three subscales were combined to calculate an overall score for internalizing symptoms

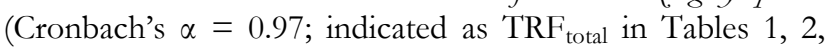
and 3).

\section{Physiological measurements and data reduction}

Saliva samples were obtained using the passive method over a two-minute time period on two days (Navazesh, 1993). On both days, two saliva samples were collected at home. The subjects were instructed on both mornings to avoid eating or brushing their teeth until the sampling had been completed. The first sample was taken immediately after awakening and the second was taken 30 minutes later. Parents supervised the children in the collection and conservation of samples, which were immediately frozen at home at $-20^{\circ} \mathrm{C}$ and picked up later that day. For free cortisol measurement, $500 \mu \mathrm{l}$ of saliva were taken for analysis using an automatized assay system (salivary cortisol on ROCHE Elecsys immunoassay system; see Chiu, Collier, Clark, \& Wynn-Edwards, 2003, and Vogeser, Durner, Seliger, \& Auernhammer, 2006, for more details). This system does not require duplicate analysis of each saliva sample. Cortisol levels were expressed in nmol/l. For the sAA activity and output assays, an enzymatic colorimetric assessment was used (see Maldonado et al., 2008, and Sánchez-Navarro, Maldonado, Martínez-Selva, Enguix, \& Ortiz, 2012, for more details). sAA activity is considered as a measurement of the enzymatic activity of this enzyme in saliva $(\mathrm{U} / \mathrm{ml})$ whereas sAA output is a measurement of the secretion of this enzyme over time $(\mathrm{U} / \mathrm{min})$. Intra- and inter- $\mathrm{CV}$ were not calculated for cortisol or sAA in this study.

For statistical analyses, we reduced the raw salivary data. Only those participants who had collected all four samples 
were included in the statistical analyses. Salivary measurements of $\alpha$-amylase activity and output, cortisol, delta cortisol (defined as the difference between the +30 min measurement of cortisol minus the awakening time cortisol measure), and the sAA/cortisol ratio were averaged over the two days of observation using the four data measurements from each participant. In case of violation of the normality assumption, the data were square-root transformed (in the case of psychological measurements) or natural-log transformed $(\ln (\mathrm{x}-1)$ in the case of sAA activity, output, and sAA/cortisol ratio). The less-drastic data transformation was always employed, pursuant to the indications of Tabachnick and Fidell, 2013. The cortisol and delta cortisol data did not require any transformation.

\section{Statistical analyses and data reduction}

Our statistical analyses were conducted using a two-step strategy:

(1) First, descriptive statistics for age, anthropometric, sociodemographic (parental education and income), perceived socioeconomic status (SES) with respect to the country or city, psychological (TRF scores) and salivary measurements for the total sample and according to gender were calculated.

(2) For data reduction, we carried out the following steps:

(2.1.) Initially, we conducted an exploratory analysis to assess whether internalizing symptoms scores were linked to salivary markers through bivariate partial correlations (after controlling for age and BMI as indirect indicators of development) for the full sample and, separately, for both genders.
(2.2.) We then conducted various simple linear regression analyses (using the stepwise method) on the total sample to determine the relative predictive power of the analytes in question on TRF scores. After this step, and in accordance with our results, we specifically tested the moderating role of gender on the associations between sAA activity and the depressionwithdrawal subscale of TRF.

Data were analyzed using the Statistical Package for Social Science version 22 (SPSS Institute, Chicago, IL). For all analyses, $p$-values $<.05$ were considered significant. Unless otherwise indicated, all results shown in figures are mean \pm standard deviation (SD) (obtained from untransformed data) to facilitate comparison with other studies.

\section{Results}

No significant differences were observed in age, anthropometric, socio-demographic, psychological (TRF) data, or salivary measurements between the boys and girls included in our sample (Table 1). No significant differences were observed in bedtime, awakening time, time of later sampling (30 min), subjective sleep quality or the method of awakening on days 1 and 2 of the observation, all of which are determinants for morning levels of cortisol and sAA (data not shown owing to space limitations). Only gender, age and body mass index were included as control variables in our statistical analyses.

Table 1. Descriptive statistics and comparison between genders for age, body mass index (BMI), family income per month, perceived socio-economic status with respect to country (Spain) and city (Malaga), parental education, Teacher's Report Form scores, and salivary measures in our community sample (mean $\pm S D)$.

\begin{tabular}{|c|c|c|c|c|}
\hline Parameters & Full sample & Boys & Girls & Contrast \\
\hline Age & $9.19 \pm 1.20$ & $9.27 \pm 1.21$ & $9.13 \pm 1.21$ & $U=1131.50^{\#}$ \\
\hline BMI & $\begin{array}{l}20.68 \pm 3.09 \\
(12.82-31.60) \\
(n=99)\end{array}$ & $\begin{array}{l}20.83 \pm 4.08 \\
(14.88-31.60) \\
(n=45)\end{array}$ & $\begin{array}{l}20.55 \pm 3.84 \\
(12.82-28.84) \\
(n=54)\end{array}$ & $U=1085.50^{\#}$ \\
\hline $\begin{array}{l}\text { Family income per month } \\
\text { (in Euros) }\end{array}$ & $\begin{array}{l}1915.21 \pm 1528.17 \\
(250-15000) \\
(n=99)\end{array}$ & $\begin{array}{l}2051.81 \pm 2113.65 \\
(350-15000) \\
(n=44)\end{array}$ & $\begin{array}{l}1795.00 \pm 693.05 \\
(250-3200)\end{array}$ & $\begin{array}{l}t=0.81^{\#} \\
\text { d.f. }=92 \\
(n=50)\end{array}$ \\
\hline Perceived SES Country & $\begin{array}{l}5.87 \pm 1.03 \\
(1-10) \\
(n=99)\end{array}$ & $\begin{array}{l}5.79 \pm 1.00 \\
(4-8) \\
(n=39)\end{array}$ & $\begin{array}{l}5.94 \pm 1.51 \\
(1-10) \\
(n=52)\end{array}$ & $U=9202.50^{\#}$ \\
\hline Perceived SES $S_{\text {City }}$ & $\begin{array}{l}6.71 \pm 1.70 \\
(3-10) \\
(n=99)\end{array}$ & $\begin{array}{l}6.43 \pm 1.58 \\
(4-10) \\
(n=39)\end{array}$ & $\begin{array}{l}6.92 \pm 1.76 \\
(3-10) \\
(n=52)\end{array}$ & $U=835^{\#}$ \\
\hline Parental education & & & & Fisher's exact test \\
\hline Fathers & & & & $0.45^{\#}$ \\
\hline Primary school studies & 50 & 21 & 29 & \\
\hline Secondary school studies & 20 & 8 & 12 & \\
\hline Bachelor's degree & 11 & 5 & 6 & \\
\hline Master's degree & 10 & $\begin{array}{l}5 \\
(n=39)\end{array}$ & $\begin{array}{l}5 \\
(n=52)\end{array}$ & \\
\hline
\end{tabular}




\begin{tabular}{|c|c|c|c|c|}
\hline Parameters & Full sample & Boys & Girls & Contrast \\
\hline Mothers & & & & $2.43^{\#}$ \\
\hline Primary school studies & 44 & 20 & 24 & \\
\hline Secondary school studies & 25 & 9 & 16 & \\
\hline Bachelor's degree & 16 & 9 & 7 & \\
\hline Master's degree & 11 & $\begin{array}{l}5 \\
(n=43)\end{array}$ & $\begin{array}{l}6 \\
(n=53)\end{array}$ & \\
\hline \multicolumn{5}{|l|}{ TRF scores } \\
\hline $\mathrm{TRF}_{\text {anxiety }}$ & $\begin{array}{l}3.55 \pm 3.58 \\
(0-16) \\
(n=98)\end{array}$ & $\begin{array}{l}3.90 \pm 3.60 \\
(0-12) \\
(n=44)\end{array}$ & $\begin{array}{l}3.25 \pm 3.57 \\
(0-16) \\
(n=54)\end{array}$ & $\begin{array}{l}t=0.650^{\#} \\
\text { d.f. }=97\end{array}$ \\
\hline $\begin{array}{l}\text { TRF }_{\text {depression-withdrawal }} \\
(0-11)\end{array}$ & $\begin{array}{l}2.69 \pm 3.05 \\
(0-11) \\
(n=98)\end{array}$ & $\begin{array}{l}3.36 \pm 3.45 \\
(0-10) \\
(n=44)\end{array}$ & $\begin{array}{l}2.14 \pm 2.58 \\
\text { d.f. }=97 \\
(n=54)\end{array}$ & $t=1.846^{\#}$ \\
\hline $\mathrm{TRF}_{\text {psychosomatic }}$ & $\begin{array}{l}0.98 \pm 1.54 \\
(0-6) \\
(n=98)\end{array}$ & $\begin{array}{l}1.00 \pm 1.41 \\
(0-6) \\
(n=44)\end{array}$ & $\begin{array}{l}0.98 \pm 1.65 \\
(0-6) \\
(n=54)\end{array}$ & $\begin{array}{l}t=0.600^{\#} \\
\text { d.f. }=97\end{array}$ \\
\hline $\mathrm{TRF}_{\text {total }}$ & $\begin{array}{l}7.23 \pm 6.27 \\
(0-22) \\
(n=98)\end{array}$ & $\begin{array}{l}8.27 \pm 6.15 \\
(0-22) \\
(n=44)\end{array}$ & $\begin{array}{l}6.38 \pm 6.29 \\
(0-22) \\
(n=54)\end{array}$ & $\begin{array}{l}t=1.464^{\#} \\
\text { d.f. }=97\end{array}$ \\
\hline \multicolumn{5}{|l|}{ Salivary measures } \\
\hline Mean cortisol (nmol/l) & $\begin{array}{l}7.66 \pm 2.94 \\
(2.47-17.02) \\
(n=99)\end{array}$ & $\begin{array}{l}7.56 \pm 2.99 \\
(2.47-15.76) \\
(n=45)\end{array}$ & $\begin{array}{l}7.74 \pm 2.92 \\
(2.91-17.02) \\
(n=54)\end{array}$ & $\begin{array}{l}t=-0.302^{\#} \\
\text { d.f. }=97\end{array}$ \\
\hline $\begin{array}{l}\text { Delta cortisol }(\mathrm{nmol} / \mathrm{l}) \\
(-8.16-13.43)\end{array}$ & $\begin{array}{l}2.00 \pm 3.76 \\
(-6.17-8.79) \\
(n=99)\end{array}$ & $\begin{array}{l}0.94 \pm 3.05 \\
(-8.16-13.43) \\
(n=45)\end{array}$ & $\begin{array}{l}2.88 \pm 4.08 \\
\text { d.f. }=97 \\
(n=54)\end{array}$ & $t=-2.625 * *$ \\
\hline Mean sAA Activity (U/ml) & $\begin{array}{l}6.77 \pm 2.35 \\
(1.32-14.00) \\
(n=99)\end{array}$ & $\begin{array}{l}6.28 \pm 2.48 \\
(1.32-14.00) \\
(n=45)\end{array}$ & $\begin{array}{l}7.18 \pm 2.16 \\
(3.00-13.15) \\
(n=54)\end{array}$ & $\begin{array}{l}t=-1.926 \# \\
\text { d.f. }=97\end{array}$ \\
\hline Mean sAA Output (U/min) & $\begin{array}{l}5.30 \pm 2.20 \\
(0.88-13.05) \\
(n=99)\end{array}$ & $\begin{array}{l}4.64 \pm 2.11 \\
(0.88-9.71) \\
(n=45)\end{array}$ & $\begin{array}{l}5.85 \pm 2.13 \\
(1.45-13.05) \\
(n=54)\end{array}$ & $\begin{array}{l}t=-2.815^{* *} \\
\text { d.f. }=97\end{array}$ \\
\hline Mean Ratio sAA Activity/Cortisol & $\begin{array}{l}0.75 \pm 0.34 \\
(-0.54-1.57) \\
(n=99)\end{array}$ & $\begin{array}{l}0.68 \pm 0.37 \\
(-0.54-1.57) \\
(n=45)\end{array}$ & $\begin{array}{l}0.81 \pm 0.31 \\
(-0.11-1.37) \\
(n=54)\end{array}$ & $\begin{array}{l}t=-1.874 \# \\
\text { d.f. }=97\end{array}$ \\
\hline Mean Ratio sAA Output/Cortisol & $\begin{array}{l}0.50 \pm 0.46 \\
(-0.92-1.39) \\
(n=99)\end{array}$ & $\begin{array}{l}0.38 \pm 0.50 \\
(-0.92-1.38) \\
(n=45)\end{array}$ & $\begin{array}{l}0.61 \pm 0.41 \\
(-0.46-1.39) \\
(n=54)\end{array}$ & $\begin{array}{l}t=-2.463 * * \\
\text { d.f. }=97\end{array}$ \\
\hline
\end{tabular}

$\#$ n.s.; $\nmid p=.10 ;{ }^{*} p<.05 ; * * p<.01$

\section{Association of internalizing psychopathology scores with salivary measures}

Statistically significant partial Pearson product-moment correlation coefficients were observed among two subscales of TRF (the depression-withdrawal subscale and the total internalizing score in TRF) and mean levels of morning sAA activity $(r=-.213, p<.05, n=99 ; r=-.222 ; p<.05, n=99$, respectively). Moreover, various moderately-statistically sig- nificant partial Pearson product-moment correlation coefficients between TRF subscores and the salivary measures emerged when we repeated the same analysis exclusively on the subset of girls (Table 2). Thus, the depression-withdrawal subscore of TRF was inversely related to different salivary measurements (Mean sAA activity: $r=-.343, p<.05, n=54$; Mean ratio sAA activity/cortisol: $r=-.314, p<.05, n=54$ ). Nevertheless, these analyses yielded negative results in the subset of boys (Table 3).

Table 2. Partial correlations between Teacher's Report Form scores and salivary markers after controlling for age and body mass index (BMI) in girls $(n=$ 54).

\begin{tabular}{|c|c|c|c|c|}
\hline & $\mathrm{TRF}_{\text {anxiety }}$ & $\mathrm{TRF}_{\text {depression-withdrawal }}$ & $\mathrm{TRF}_{\text {psychosomatic }}$ & $\mathrm{TRF}_{\text {total }}$ \\
\hline Mean cortisol & 0.009 & -0.053 & -0.056 & -0.035 \\
\hline Mean delta cortisol & 0.016 & 0.128 & -0.126 & 0.009 \\
\hline Mean sAA activity & -0.148 & $-0.343 *$ & -0.171 & $-0.284+$ \\
\hline Mean sAA output & -0.169 & -0.137 & -0.204 & -0.216 \\
\hline sAA activity/cortisol Ratio & 0.169 & $-0.314 *$ & -0.127 & $-0.257+$ \\
\hline sAA output/cortisol Ratio & 0.194 & -0.153 & -0.193 & $-0.232+$ \\
\hline
\end{tabular}

$+p=.10 ; * p<.05 ; * *<<.01$ 
Table 3. Partial correlations between Teacher's Report Form scores and salivary markers after controlling for age and body mass index (BMI) in boys $(n=$ 45).

\begin{tabular}{|c|c|c|c|c|}
\hline & TRF $_{\text {anxiety }}$ & $\mathrm{TRF}_{\text {depression-withdrawal }}$ & TRF $_{\text {psychosomatic }}$ & $\mathrm{TRF}_{\text {total }}$ \\
\hline Mean cortisol & -0.180 & 0.020 & 0.072 & -0.064 \\
\hline Mean delta cortisol & 0.176 & 0.098 & -0.118 & 0.135 \\
\hline Mean sAA activity & -0.196 & -0.006 & -0.061 & -0.107 \\
\hline Mean sAA output & -0.072 & -0.042 & 0.015 & -0.044 \\
\hline sAA activity/cortisol Ratio & -0.114 & 0.035 & -0.134 & -0.066 \\
\hline sAA output/cortisol Ratio & 0.070 & -0.008 & -0.070 & 0.02 \\
\hline
\end{tabular}

$+p=.10 ;{ }^{*} p<.05 ; * *<.01$

\section{Simple linear regression models of salivary measures on TRF scores}

To deterine the best salivary predictor of each TRF internalizing subscale in the sample as a whole, we performed simple linear regression analyses using the stepwise method for all salivary biomarkers on each of the TRF internalizing subscales. In the full sample, sAA activity fit best with the depression-withdrawal TRF subscore and the total TRF score. In Model $1(\beta=-.213, t=-2.149, p<.05)$, sAA activity $[F(1,97)=4.620, p<.05]$ explained $4.5 \%$ of the total variance in the depression-withdrawal subscore of TRF $\left(\mathrm{R}^{2}=\right.$ .045 , Tolerance $=1, \mathrm{VIF}=1$, Condition Index $=.097$; see Figure 1) whereas in Model $2(\beta=-.221, t=-2.232, p<.05)$, sAA activity $[F(1,97)=4.980, p<.05]$ explained $4.9 \%$ of the total variance in the total score of TRF $\left(R^{2}=.049\right.$, Tolerance $=1, \mathrm{VIF}=1$, Condition Index $=.097$ ).

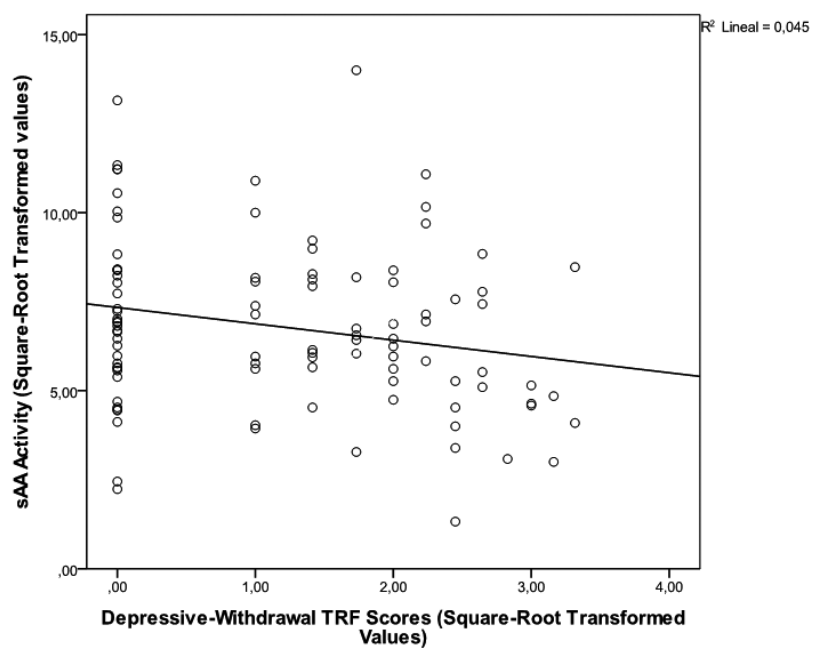

Figure 1. Square-root transformed values of morning salivary alphaamylase activity on square-root transformed values of the TRF depressionwithdrawal subscale $(n=99)$.

According to the different results obtained in our exploratory analyses for boys and girls described in the previous section, we examined the possible moderating role of gender in regards to the association between sAA activity and depressive symptoms. The interaction analysis (Model 3) was not statistically significant for sAA activity $(\beta=-.014, \mathrm{SE}=$ .064 , Beta $=-.031, t=-.222, p=.825)$, gender $(\beta=.687, \mathrm{SE}$ $=.663$, Beta $=.315, t=1.036, p=.303)$, or for the interac- tion of sAA activity by gender $(\beta=-0.150, \mathrm{SE}=0.093$, Beta $=-0.539, t=-1.616, p=.109)$. In sum, low levels of sAA activity were associated with an increased score in depressive symptoms and total score on the TRF in the whole sample, and gender was not a moderator of the association between sAA activity and TRF scores despite the differences observed in our previous exploratory analyses.

\section{Discussion}

The main finding of our cross-sectional study was that in the entire sample of our participants, the best predictor of a higher level of depressive/withdrawal and overall internalizing symptoms was reduced levels of morning sAA activity. In other words, an inverse relationship was shown between levels of depressive/withdrawal and overall internalizing symptoms and mean levels of morning sAA activity in our community sample of children. This result was entirely unexpected, as it contradicts some of the previous scientific literature on this issue. Nevertheless, this unexpected result could represent a promising finding in this field of research since recent epidemiological studies have suggested some limitations of morning salivary cortisol levels in predicting high risk of developing initial MDE onset in young adult females (Owens et al., 2014). According to our results, it is probable that sAA could overcome this limitation in future studies.

The potential use of sAA as an indirect marker of psychopathology is not entirely new in the scientific literature on the usefulness of sAA activity as a biomarker of child and adolescent psychopathology. In 2010, Vigil et al. suggested that sAA activity might be employed in future studies as a promising salivary biomarker of depressive symptoms in adolescent samples. In a study conducted on adolescents displaced by Hurricane Katrina and living in a U.S. government relocation camp $(n=62)$ and a gender- and agematched control group $(n=53)$, gender was found to be a moderator variable in the relationship between sAA activity and levels of depressive symptoms. In that study, higher sAA levels among youths (both control and relocated participants) were associated with lower scores of depression, albeit exclusively in male participants. Despite the novelty and potential usefulness of this finding (Vigil et al., 2010), such a relationship between depressive symptoms and sAA activity was obtained without strict control of circadian variations in this enzyme (Rohleder \& Nater, 2009). Indeed, Vigil et al. (2010) 
obtained just two saliva samples (separated by an interval of 1.5 hours, during which time various psychological measures were obtained from participants) within a wide circadian interval of time (10:50-18:50). This discrepancy between our result and that of Vigil et al. (related to the specific role of male gender as a moderator variable) is likely due to differences in the type of psychopathology studied (i.e. PostTraumatic Stress Disorder vs. Major Depressive Disorder (MDD)) and differences in methodological aspects between both studies. In this last aspect, for example, Veen et al. (2013) have recently observed differences in evening basal sAA activity levels between patients who have MDD and controls. Nevertheless, additional potentially-confounding factors could include the older age of participants, exposure to a traumatic stressor, or the time elapsed from trauma to the measurement of sAA activity.

In contrast to the study by Vigil et al., our measurements of sAAAR were taken in accordance with the indications given by Rohleder \& Nater, 2009. In our cross-sectional study, we obtained two saliva measurements on two different school days, one upon awakening and a second 30 minutes after awakening. Both measurements were averaged to produce a mean value (mean levels of morning sAA activity or output). Therefore, from a circadian point of view, the finding shown here is more reliable than the result presented by Vigil et al. (2010), as it avoids the possible effect of midday or evening differences in sAA levels (Veen et al., 2013).

When our main finding is compared with the results obtained in adult samples with more severe diagnoses of MDD, the assessment of sAA activity is inconclusive (Bagley et al., 2011; Ishitobi et al., 2010; Tanaka et al., 2012; Veen et al., 2013). Although Braithwaite et al. (2015) have reported an association between depressive symptoms in later pregnancy and elevated awakening sAA activity levels in comparison with non-depressed controls, Cubala \& Landowski (2014) found that low levels of sAA activity were observed in drugnaïve adult patients suffering a first MDE. Our results show that low morning levels of sAA could have a role as a possible risk factor. To explain these findings, some researchers have speculated that SAA activity could be a potential surrogate marker for the level of noradrenaline in the central nervous system (CNS) (Buchanan, Bilbas, \& Adolphs, 2010; Ehlert, Erni, Hebisch, \& Nater, 2006; Nater \& Rohleder, 2009; Rohleder, Nater, Wolf, Ehlert, \& Kirschbaum, 2004; Rohleder \& Nater, 2009; Sanchez-Navarro et al., 2012; Van Stegeren et al., 2006). Other recent studies have reported that this association between SAA and peripheral noradrenaline is statistically significant when it is measured in healthy subjects confronted by psychosocial laboratory stressors (Ditzen, Ehlert, \& Nater, 2014). Decreased morning noradrenergic transmission is a well-established pathophysiological finding in MDD patients (Hamon \& Blier, 2013). Thus, lower sAA activity could be expected in depressed patients relative to controls (Cubala \& Landowski, 2014; Vigil et al., 2010). According to the monoamine theory, low levels of monoamines (including noradrenaline) represent one of the main neurochemical impairments related to depression (Kiss, 2008). Therefore, from a neurochemical perspective, our findings might suggest that low levels of morning sAA activity may be reflecting a biological trait of risk in the form of low levels of morning peripheral noradrenaline. Low morning sAA levels could, therefore, be a biological trait of a phenotype that expresses high levels of depressive symptoms even before the onset of a MDE. After repeated exposure to life stressors, this trait may facilitate the development of depression. Indeed, longitudinal studies are needed to clarify the link between central noradrenaline and sAA activity levels and only future prospective studies will shed light on this issue. These same studies will help determine the exact relevance of these early differences in morning sAA levels, an objective that is beyond the reduced scope of this crosssectional study but which is important to the advancement of knowledge on this issue.

Finally, the lack of association between morning levels of cortisol, delta cortisol, or sAA/cortisol ratios observed in our study are findings that must be discussed in detail. Elevated or reduced morning cortisol levels have been shown to be associated with an elevated risk of a MDE in numerous studies (Dietrich et al., 2013; Nederhof et al., 2015; Owens et al., 2014). The difficulties of observing these associations in our sample could be related to the small number of participants and especially to the selection of healthy participants. The majority of the studies reviewed in the introductory section included children or adolescents who have clinical levels of depression or mothers who have different forms of depression. Nevertheless, other limitations or weaknesses in our study must be considered in this respect. These limitations affect the interpretation of our final results and their generalization. For example, we did not use any digital system nor did we telephone the parents to control the accuracy of saliva sampling at home. However, the reliability of morning cortisol levels in comparison with similar studies (see, for example, Ulrike, Reinhold, \& Dirk, 2013) and morning levels of sAA over the two days of observation were similar to other studies, including those with child community participants (see, for example, Maldonado et al., 2008, and Funke et al., 2015). Additionally, the control of well-known determinants and confounders of both markers (cortisol and sAA) such as age, gender, and BMI were taken into account. Thirdly, given the cross-sectional nature of our study, only associations not causality - can be established among these variables. Only longitudinal studies with high- and low-risk populations could determine the usefulness of sAA in this respect. Fourthly, we did not control possible differences in prepubertal and pubertal development in girls, though in correlational statistical analyses, the effect of age and BMI were controlled. Fifthly, withdrawal/depressive symptoms were only assessed via observations made by teachers and could not be completed by means of self-reporting or parent reports.

In conclusion, the main finding of our cross-sectional study is that higher levels of depressive/withdrawal and 
overall internalizing symptomatology can best be predicted by morning measurement of SAA activity level relative to other salivary biomarkers in boys and girls in a community sample. Lower levels of sAA activity are likely to be related

\section{References}

Adam, E.K., Doane, L.D., Zinbarg, R.E., Mineka, S., Craske, M.G., \& Griffith, J.W. (2010). Prospective prediction of major depressive disorder from cortisol awakening responses in adolescence. Psychoneuroendocrinology, $\quad 35, \quad 921-931 . \quad$ DOI: http://dx.doi.org/10.1016/j.psyneuen.2009.12.007

Ali, N., \& Pruessner, J.C. (2012). The salivary alpha amylase over cortisol ratio as a marker to assess dysregulations of the stress systems. Physiology Behavior, 106, 65-72. DOI: http://dx.doi.org/10.1016/j.physbeh.2011.10.003

Bagley, S.L., Weaver, T.L., \& Buchanan, T.W. (2011). Sex differences in physiological and affective responses to stress in remitted depression. Physiology \& Behavior, 104, 180-186. DOI: http://dx.doi.org/10.1016/j.physbeh.2011.03.004

Bauer, A.M., Quas, J.A., \& Boyce, W.T. (2002). Associations between physiological reactivity and children's behavior: advantages of a multisystem approach. Journal of Developmental and Behavioral Pediatrics, 23, 102-113. DOI: http://dx.doi.org/10.1097/00004703-200204000-00007

Blair, C., Granger, D., \& Razza, R.P. (2005). Cortisol reactivity is positively related to executive function in preschool children attending Head Start. Child Development, 76, 554-567. DOI: http://dx.doi.org/10.1111/j.1467-8624.2005.00863.x

Braithwaite, E.C., Ramchamandani, P.G., Lane, T.A., \& Murphy, S.E. (2015). Symptoms of prenatal depression are associated with raised salivary alpha-amylase levels. Psychoneuroendocrinology, 60, 163-172. DOI:http://dx.doi.org/10.1016/j.psyneuen.2015.06.013

Buchanan, T.W., Bilbas, D., \& Adolphs. R. (2010). Salivary a-amylase levels as a biomarker of experienced fear. Communicative and Integrative Biology, 3, 525-527. DOI: http://dx.doi.org/10.4161/cib.3.6.12606

Chiu, S.K., Collier, C.P., Clark, A.F., \& Wynn-Edwards, K.E.(2003). Salivary cortisol on ROCHE Elecsys immunoassay system: Pilot biological variation studies. Clinical Biochemistry, 36, 211-214. http://dx.doi.org/10.1016/S0009-9120(02)00471-X

Chrousos, G.P. (2009). Stress and disorders of the stress system. Nature Re$\begin{array}{llll}\text { views } & \text { Endocrinology, } & 5, & 374-381 .\end{array}$ http://dx.doi.org/10.1038/nrendo.2009.106

Cubała, W.J., \& Landowski, J. (2014). Low baseline salivary alpha-amylase in drug-naïve patients with short-illness-duration first episode major depressive disorder. Journal of Affective Disorders, 157, 14-17. DOI: http://dx.doi.org/10.1016/j.jad.2013.12.043

Dietrich, A., Ormel, J., Buitelaar, J.K., Verhulst, F.C., Hoekstra, P.J., \& Hartman, C.A. (2013). Cortisol in the morning and dimensions of anxiety, depression, and aggression in children from a general population and clinic-referred cohort: an integrative analysis. The TRAILS study. $\begin{array}{llll}\text { Psychoneuroendocrinology, } & 38, & \text { 1281-1298. DOI: }\end{array}$ http://dx.doi.org/10.1016/j.psyneuen.2012.11.013

Ditzen, B., Ehlert, U., \& Nater, U.M. (2014). Associations between salivary alpha-amylase and catecholamines - A multilevel modeling approach. Biological Psychology, $103, \quad 15-\quad 18 . \quad$ DOI: http:/ /dx.doi.org/10.1016/j.biopsycho.2014.08.001

Domènech-Llaberia, E., Viñas, F., Pla, E., Jané, M.C., Mitjavila, M., Corbella, T., \& Canals, J. (2009). Prevalence of major depression in preschool children. European Child \& Adolescent Psychiatry, 18(10), 597-604. DOI: http://dx.doi.org/10.1007/s00787-009-0019-6

Dougherty, L.R., Klein, D.N., Olino, T.M., Dyson, M., \& Rose, S. (2009). Increased waking salivary cortisol and depression risk in preschoolers: the role of maternal history of melancholic depression and early child temperament. Journal of Child Psychology and Psychiatry, 50, 1495-1503. DOI: http://dx.doi.org/10.1111/j.1469- 7610.2009.02116.x

Dougherty, L.R., Smith, V.C., Olino, T.M., Dyson, M.W., Bufferd, S.J., Rose, S.A., \& Klein, D.N. (2013). Maternal psychopathology and early to reduced peripheral noradrenergic activity and, moreover, might represent a biological diathesis for the future onset of a MDE, which could ultimately be unleashed by the repeated impact of day-to-day and life stressors in the future. child temperament predict young children's salivary cortisol 3 years later. Journal of Abnormal Child Psychology, 41, 531-542.

Ehlert, U., Erni, K., Hebisch, G., \& Nater, U. (2006). Salivary alphaamylase levels after yohimbine challenge in healthy men. The Journal of Clinical Endocrinology and Metabolism, 91, 5130-5133. DOI: http://press.endocrine.org/doi/abs/10.1210/jc.2006-0461

Fonseca-Pedrero, E., Paino, M., Lemos-Giráldez, S., \& Muñiz, J. (2011). Prevalence and characteristics of depressive symptomatology in nonclinical adolescents. Actas Españolas de Psiquiatría, 39(4), 217-225.

Funke, R., Eichler, A., Distler, J., Golub, Y., Kratz, O., \& Moll, G.H. (2015). Stress system dysregulation in pediatric generalized anxiety disorder associated with comorbid depression. Stress and Health. DOI: http://dx.doi.org/10.1002/smi.2736

Goodyer, I.M., Herbert, J., Altham, P.M.E., Pearson, J., Secher, S.M., \& Shiers, H.M. (1996). Adrenal secretion during major depression in 8- to 16-year-olds, I. Altered diurnal rhythms in salivary cortisol and dehydroepiandrosterone (DHEA) at presentation. Psychological Medicine, 26, 245-256. DOI: http://dx.doi.org/10.1017/S0033291700034644

Goodyer, I.M., Herbert, J., \& Altham, P.M. (1998). Adrenal steroid secretion and major depression in 8- to 16-year-olds, III. Influence of cortisol/DHEA ratio at presentation of subsequent rates of disappointing life events and persistent major depression. Psychological Medicine, 28, 265-273. DOI: http://dx.doi.org/10.1017/S0033291797006314

Halligan, S.L., Herbert, J., Goodyer, I.M., \& Murray, L. (2004). Exposure to postnatal depression predicts elevated cortisol in adolescent offspring. Biological Psychiatry, 55, 376-381. DOI: http://dx.doi.org/10.1016/j.biopsych.2003.09.013

Halligan, S.L., Herbert, J., Goodyer, I., \& Murray, L. (2007). Disturbances in morning cortisol secretion in association with maternal postnatal depression predict subsequent depressive symptomatology in adolescents. Biological Psychiatry, 62, 40-46. DOI: http://dx.doi.org/10.1016/j.biopsych.2006.09.011

Hamon, M., \& Blier, P. (2013). Monoamine neurocircuitry in depression and strategies for new treatments. Progress in Neuro-psychopharmacology Bi$\begin{array}{llll}\text { ological Psychiatry, } & \text { 45, 54-63. }\end{array}$ http://dx.doi.org/10.1016/i.pnpbp.2013.04.009

Herbert, J., Goodyer, I.M., Altham, P.M.E., Pearson, J., Secher, S.M., \& Shiers, H.M. (1996). Adrenal secretion and major depression in 8- to 16 -year-olds, II. Influence of co-morbidity at presentation. Psychological Medicine, 26, 257-263. DOI: http://dx.doi.org/10.1017/S0033291700034656

Ishitobi, Y., Akiyoshi, J., Tanaka, Y., Ando, T., Okamoto, S., Kanehisa, M.,...Kodama, K. (2010). Elevated salivary $\alpha$-amylase and cortisol levels in unremitted and remitted depressed patients. International Journal of Psychiatry in Clinical Practice, 14, 268- 273. DOI: http://dx.doi.org/10.3109/13651501.2010.500737

Keenan, K., Hipwell, A., Babinski, D., Bortner, J., Henneberger, A., Hinze, A., Klostermann, S., Rischall, M., \& Sapotichne, B. (2013). Examining the developmental interface of cortisol and depression symptoms in young adolescent girls. Psychoneuroendocrinology, 38, 2291-2299. DOI: http://dx.doi.org/10.1016/j.psyneuen.2013.04.017

Kendler, K.S., \& Gadner, C.O. (2014). Sex differences in pathways to major depression: a study of opposite twin pairs. American Journal of Psychiatry, $171, \quad 426-435 . \quad$ DOI: http://dx.doi.org/10.1176/appi.ajp.2013.13101375

Kirschbaum, C., \& Hellhammer, D.H. (1989). Salivary cortisol in psychobiological research: an overview. Neuropsychobiology, 22, 150-169. DOI: http://dx.doi.org/10.1159/000118611

Kiss, J.P. (2008). Theory of active antidepressants: A nonsynaptic approach to the treatment of depression. Neurochemistry International, 52, 34-39. DOI: http://dx.doi.org/10.1016/j.neuint.2007.04.006 
Kuhlman, K.R., Olson, S.L., \& Lopez-Duran, N.L. (2014). Predicting developmental changes in internalizing symptoms: examining the interplay between parenting and neuroendocrine stress reactivity. Developmental Psychopathology, 56, 908-923. DOI: http://dx.doi.org/10.1002/dev.21166

Lewis, G., Jones, P.B., \& Goodyer, I.M. (2016). The ROOTS study: a 10year review of findings on adolescent depression, and recommendations for future longitudinal research. Social Psychiatry and Psychiatric Epidemiology, 124, 100-110. DOI: http://dx.doi.org/10.1007/s00127-0151150-y

Maldonado, E.F., Fernandez, F.J., Trianes, M.V., Wesnes, K., Petrini, O., Zangara, A., \& Ambrosetti, L. (2008). Cognitive performance and morning levels of salivary cortisol and alpha-amylase in children reporting high vs. low daily stress perception. The Spanish Journal of Psychology, 11, 3-15.

Mendes, A.V., Loureiro, S.R., Crippa, J.A., de Meneses Gaya, C., GarcíaEsteve, L., \& Martín-Santos, R. (2012). Mothers with depression, school-age children with depression? A systematic review. Perspectives in Psychiatric Care, 48(3), 138-148. DOI: http://dx.doi.org/10.1111/j.17446163.2011.00318.x

Merwin, S.M., Smith, V.C., Kushner, M., Lemay, E.P. Jr., \& Dougherty, L.R. (2017). Parent-child adrenocortical concordance in early childhood: The moderating role of parental depression and child development. Biological Psychology, 124, 100-110. DOI: http:/ /dx.doi.org/10.1016/j.biopsycho.2017.01.013

Nater, U.M., \& Rohleder, N. (2009). Salivary alpha-amylase as a noninvasive biomarker for the sympathetic nervous system: Current state of research. Psychoneuroendocrinology, 34, 486-496. DOI: http://dx.doi.org/10.1016/j.psyneuen.2009.01.014

Navazesh, M., (1993). Methods for collecting saliva. Annals of the New York Academy of Sciences, 694, 72-77. DOI: http://dx.doi.org/10.1111/j.1749-6632.1993.tb18343.x

Nederhof, E., van Oort, F.V., Bouma, E.M., Laceulle, O.M., Oldenhinkel, A.J., \& Ormel, J. (2015). Predicting mental disorders from hypothalamic-pituitary-adrenal axis functioning: a 3 -year follow-up in the TRAILS study. Psychogical Medicine, 45, 2403-2412. DOI: http:/ /dx.doi.org/10.1017/S0033291715000392

Nelemans, S. A., Hale, W. W., Branje, S. J., van Lier, P. A., Jansen, L. M., Platje, E., ... \& Meeus, W. H. (2014). Persistent heightened cortisol awakening response and adolescent internalizing symptoms: a 3-year longitudinal community study. Journal of Abnormal Child Psychology, 42(5), 767-777. DOI: http://dx.doi.org/10.1007/s10802-013-9820-2

O 'Donnell, K.J., Glover, V., Jenkins, J., Browne, D., Ben-Shlomo, Y., Golding, J., \& O'Connor, T.G. (2013). Prenatal maternal mood is associated with altered diurnal cortisol in adolescence. Psychoneuroendocrinology, $38, \quad 1630-1638$ http://dx.doi.org/10.1016/j.psyneuen.2013.01.008

Owens, M., Herbert, J., Jones, P.B., Sahakian, B.J., Wilkinson, P.O., Dunn, V.J.,...Goodyer, I.M. (2014). Elevated morning cortisol is a stratified population- level biomarker for major depression in boys only with high depressive symptoms. Proceedings of the National Academy of Sciences, 111, 3638-3643. DOI: http://dx.doi.org/10.1073/pnas.1318786111

Rohdeler, N., Nater, U.M., Wolf, J.M., Ehlert, U., \& Kirschbaum, C. (2004). Psychosocial stress induced activation of salivary alpha-amylase: an indicator of sympathetic activity? Annals of the New York. Academy of
Sciences, 1032, 258-263. DOI http://dx.doi.org/10.1196/annals.1314.0.3

Rohleder, N., \& Nater, U.M. (2009). Determinants of salivary alpha-amylase in humans and methodological considerations. Psychoneuroendocrinology, 34, 469-485. DOI: 10.1016/j.psyneuen.2008.12.004. DOI: http://dx.doi.org/10.1016/j.psyneuen.2008.12.004

Sánchez-Navarro, J.P., Maldonado, E.F., Martínez-Selva, J.M., Enguix, A., \& Ortiz, C., (2012). Salivary alpha-amylase changes promoted by sustained exposure to affective pictures. Psychophysiology. 49, 1601-1609. DOI: http://dx.doi.org/10.1111/j.1469- 8986.2012.01475.x

Sapolsky, R.M. (2000). Stress hormones: good and bad. Neurobiology of Disease, 7, 540-542. DOI: http://dx.doi.org/10.1006/nbdi.2000.0350

Tabachnick, B.G., \& Fidell, L.S., (2013). Using Multivariate Statistics, 6th ed. Boston: Allyn and Bacon.

Tanaka, Y., Ishitobi, Y., Maruyama, Y., Kawano, A., Ando, T., Okamoto, S.,...Akiyoshi, J. (2012). Salivary alpha-amylase and cortisol responsiveness following electrical stimulation stress in major depressive disorder patients. Progress in Neuro- Psychopharmacology and Biological Psychiatry, 36, 220-224. DOI: http://dx.doi.org/10.1016/j.pnpbp.2011.10.005

Ulrike, S., Reinhold, L., \& Dirk H. (2013). Major depression in young girls is related to altered cortisol awakening response. European Child \& Adolescence Psychiatry, 22, 379-384. DOI: http://dx.doi.org/10.1007/s00787012-0371-9

Van den Bergh, B.R., \& Van Calster, B. (2009). Diurnal cortisol profiles and evening cortisol in post-pubertal adolescents scoring high on the Children's Depression Score. Psychoneuroendocrinology, 34, 791-794. DOI: http://dx.doi.org/10.1016/j.psyneuen.2008.12.008

Van Stegeren, A., Rohleder, N., Everaerd, W., \& Wolf, O.T. (2006). Salivary alpha amylase as marker for adrenergic activity during stress: Effect of betablockade. Psychoneuroendocrinology, 31, 137-141. DOI: http://dx.doi.org/10.1016/j.psyneuen.2005.05.012

Veen, G., Giltay, E.J., Licht, C.M.M., Vreeburg, S.A., Cobbaert, C.M., Penninx, B.W.J.H., \& Zitman, F.G. (2013). Evening salivary alpha-amylase, major depressive disorder, and antidepressant use in the Netherlands Study of Depression and Anxiety (NESDA). Psychiatry Research, 208, 41-46. DOI: http://dx.doi.org/10.1016/j.psychres.2013.03.012

Vigil, J.M., Geary, D.C., Granger, D.A., \& Flinn, M.V. (2010). Sex differences in salivary cortisol, alpha-amylase, and psychological functioning following Hurricane Katrina. Child Development, 81, 1228-1240. DOI: http://dx.doi.org/10.1111/j.1467- 8624.2010.01464.x

Vogeser, M., Durner, J., Seliger, E., \& Auernhammer, C., 2006. Measurement of late-night salivary cortisol with an automated immunoassay system. Clinical Chemistry and Laboratory Medicine, 44, 1441-1445. DOI: http:/ /dx.doi.org/10.1515/CCLM.2006.244

Vrshek-Schallhorn, S., Doane, L.D., Mineka, S., Zinbarg, R.E., Craske, M.G., \& Adam, E.K. (2013). The cortisol awakening response predicts major depression: predictive stability over a 4-year follow-up and effect of depression history. Psychological Medicine, 43, 483-493. DOI: http:/ /dx.doi.org/10.1017/S0033291712001213

Weissman, M. M., Pilowsky, D. J., Wickramaratne, P. J., Talati, A., Wisniewski, S. R., Fava, M., \& Cerda, G. (2006). Remissions in maternal depression and child psychopathology: a STAR* D-child report. IAMA， 295(12), 1389-1398. DOI http://dx.doi.org/10.1001/jama.295.12.1389

(Article received: 27-03-2017; revised: 28-04-2017; accepted: 09-06-2017) 